\title{
NOTES ON THE STRUCTURE AND SIGNIFICANCE OF PALAEOGYRINUS ${ }^{1}$
}

\section{By P. J. DARLington JR.}

The beetle family Palaeogyrinidæ was erected by D. H. R. von Schlechtendal in 1894 to contain the single genus Palæogyrinus, described from the obverse and reverse of a single fossil specimen from the Upper Oligocene deposites of Rott in Siebengebirge, Prussia. Concerning the later vicissitudes of the genus it should be sufficient to say that Handlirsch, in "Die Fossilen Insekten," placed it directly in the Gyrinidae, leaving it there, without a query, in Schroder's "Handbuch" and that Hatch ${ }^{2}$ has recently removed it and placed it as a separate subfamily of the Dytiscidae.

The characters given for the genus by von Schlechtendal were simple and striking. The most important was the compression of the tarsi of the middle legs for swimming, and, if the figure which accompanies the original description is accurate, the tarsi were very highly specialized indeed. The undivided eyes and the presence of a mesosternum larger than that of the Dytiscidae were considered of secondary importance. Von Schlechtendal's figure, which is repeated by Hatch, shows the external structure of the beetle in some detail, but, when considered in conjunction with the text, is obviously in part a reconstruction. Except for the tarsi, the insect is almost wholly dytiscoid.

Much might be written of Palæogyrinus as originally described, indeed remarks on its significance as a link between the Dytiscidae and the Gyrinidae have already been

1Contribution from the Entomological Laboratory of the Bussey Institution, Harvard University, No. 320.

2 Bulletin Brooklyn Entomological Society, 1927, Vol. 22, No. 2, p. 89: On page 94 will be found a bibliography of reference to Palaeogyrinus which need not be repeated here. 
published, but under the circumstances I shall refrain from a discussion and shall be content with pointing out certain facts which seem thus far to have escaped notice, and which at once reduce the matter to its simplest elements.

To return to the most important character, the structure of the middle legs, a glance at von Schlechtendal's figure will show that, in spite of the huge tarsi, comparable in their development with the swimming feet of such powerful divers as Laccophilus and Cybister, the femora are slender, and the coxae drawn so small that the whole leg is grotesquely disproportioned. Furthermore, the posterior legs have powerful femora hinged to broad coxal plates, but have no recognizable tarsi, though we should expect to find heavy ones attached to such bases. Now if tibiae should be drawn between the hind femora and the so-called middle tarsi, a pair of well-proportioned swimming legs would be formed in a position in which they are found in a good percentage of recently killed dytiscids today, and we should have to assume the loss of the imprints of only the typically slender mesotarsi, which might actually be covered by those of the heavy hind legs. Thus by a small change, and reference to the original figure will show how slight it would need to be, we should replace an anomalous and unconvincing insect by a nearly typical dytiscid, such as might well have occurred in the geological period in question. Any doubt that this suggested reconstruction is the correct one in spite of the original figure is, I think, removed by von Schlechtendal's own statement that the different parts of the posterior legs cannot be surely recognized, since they have left only slight impressions.

Among the characters of secondary importance, the entire eyes indicate at once the dytiscid affinities of the insect, as do the rest of the discernible structures except, perhaps, the mesosternum. As the latter is figured it is larger than in the Dytiscidae, but if, as we may suspect, the suture between it and the metasternum is imagined or due to a crack in the rock, we should avoid even this difficulty, for an anterior projection of the metasternum would meet the intercoxal process of the prosternum, the typical 
dytiscid condition. The so-called mesosternum should certainly be re-examined with this possibility in view.

To restate the case, Palaeogyrinus is a fossil which looks like a dytiscid, with a coxal structure demanding that the posterior and no other legs be highly developed, and which is said in the original text to be poorly preserved in the very place where the reconstruction is most remarkable. The conclusion must be that the insect was a dytiscid, but that it may have had an unusually large mesosternum. It is rather surprising that these facts have not been brought out before.

I do not believe it is possible to place Palæogyrinus accurately with relation to living genera, and see no reason to attempt it, since the placing would be a matter of guess work and might lead to confusion. The genus is interesting, therefore, chiefly because it is an example of a more or less typical dytiscid from the Upper Oligocene. It has also a temporary interest in that it provides an excuse for a few remarks on the place of fossils in the study of Coleoptera.

Among orders where there are good characters in the wing venation fossils are often reliable, as they are in other groups when good series of good specimens are available, as, for instance, in the case of the Florissant ants which have recently been studied by my friend Dr. F. M. Carpenter. Unfortunately, however, the parts of beetles which are usually preserved have few diagnostic characters, nor are good series of fossil specimens usually obtained. The placing of a species by examination of a single elytron from any but the most recent deposites must depend upon the unwarranted assumption that the beetle fauna of a given period was practically the same as that now existing. It is difficult to see the value of generic and specific descriptions of such nearly unidentifiable remains, when the greatest care and some faith are required to classify even a fairly complete specimen. This does not mean that fossil beetles have no value, but rather that their value is limited, the limit depending in each case on the number of characters actually observable in the fossil itself. There is a good deal of random guessing and specious reasoning to be 
eliminated before "Palaeocoleopterology" can be taken without a grain of salt.

I am not a palaeontologist until forced by circumstances and can make no general statement on my own responsibility, but I have discussed the matter with experienced friends who agree that, although a fossil insect may be rather loosely said to be in two dimensions, it can rarely be "adequately recorded in the form of figures" as stated by Mr. Hatch, and most emphatically should not be studied in that form alone. Indeed, the history of Palæogyrinus suggests that it may be more important to see the type of a fossil than of a living species.

European Coleoptera at Providence, R. I., in 1928.

Several specimens of Agrilus coeruleus Rossi were taken on June 16, 1926; they were determined by Mr. C. A. Frost of Framingham, Mass.

On October 12, 1919, a fine specimen of Geotrupes was taken and not being like any of the described North American species it was submitted to Mr. H. C. Fall of Tyngsboro, Mass., who stated that it resembled the European G. sylvaticus Panz. in his collection. I find that the specimen answers very well to the description of this species in Thompson's Scandinavian Insects.

J. V. Nylen, Providence, R. I. 

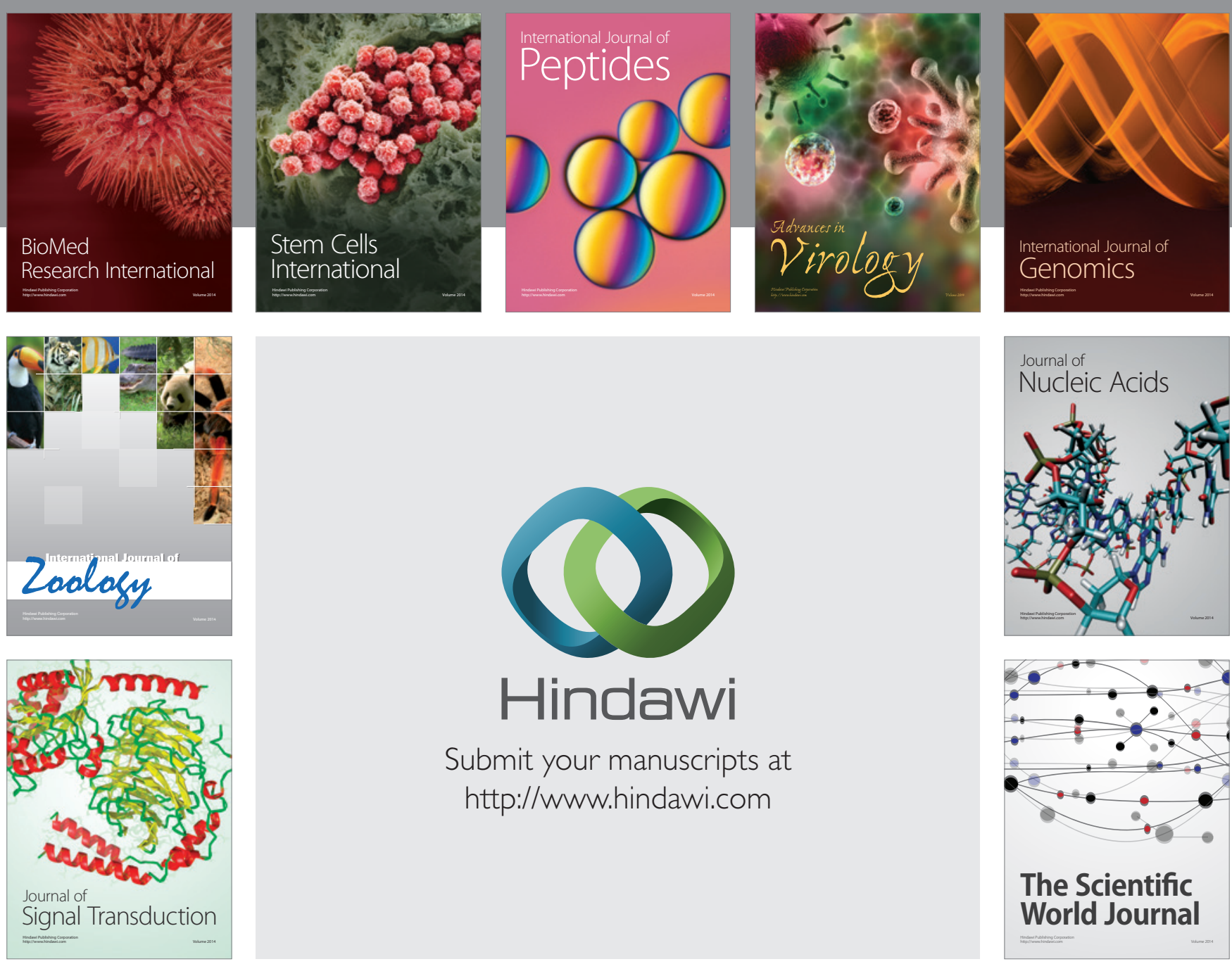

Submit your manuscripts at

http://www.hindawi.com
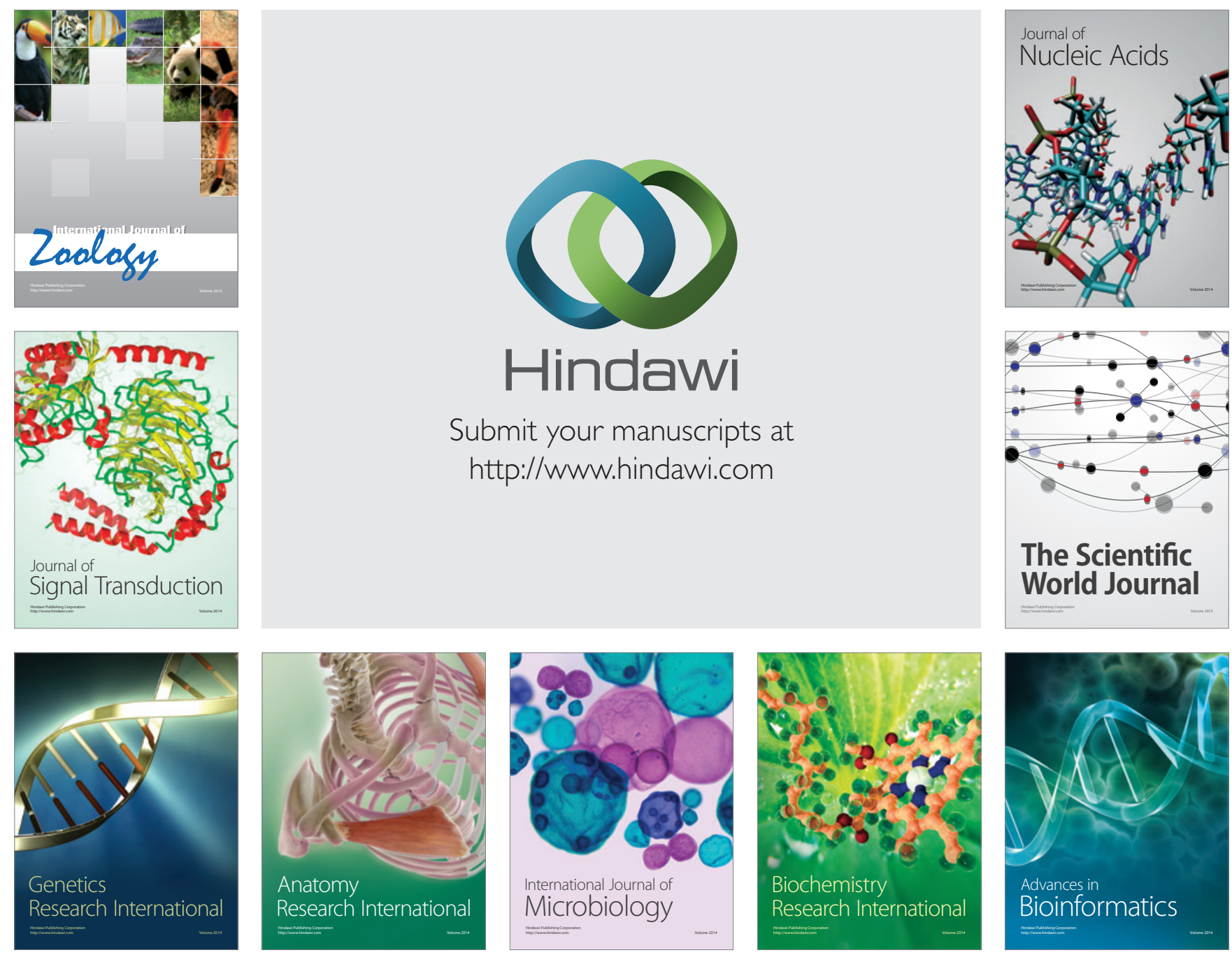

The Scientific World Journal
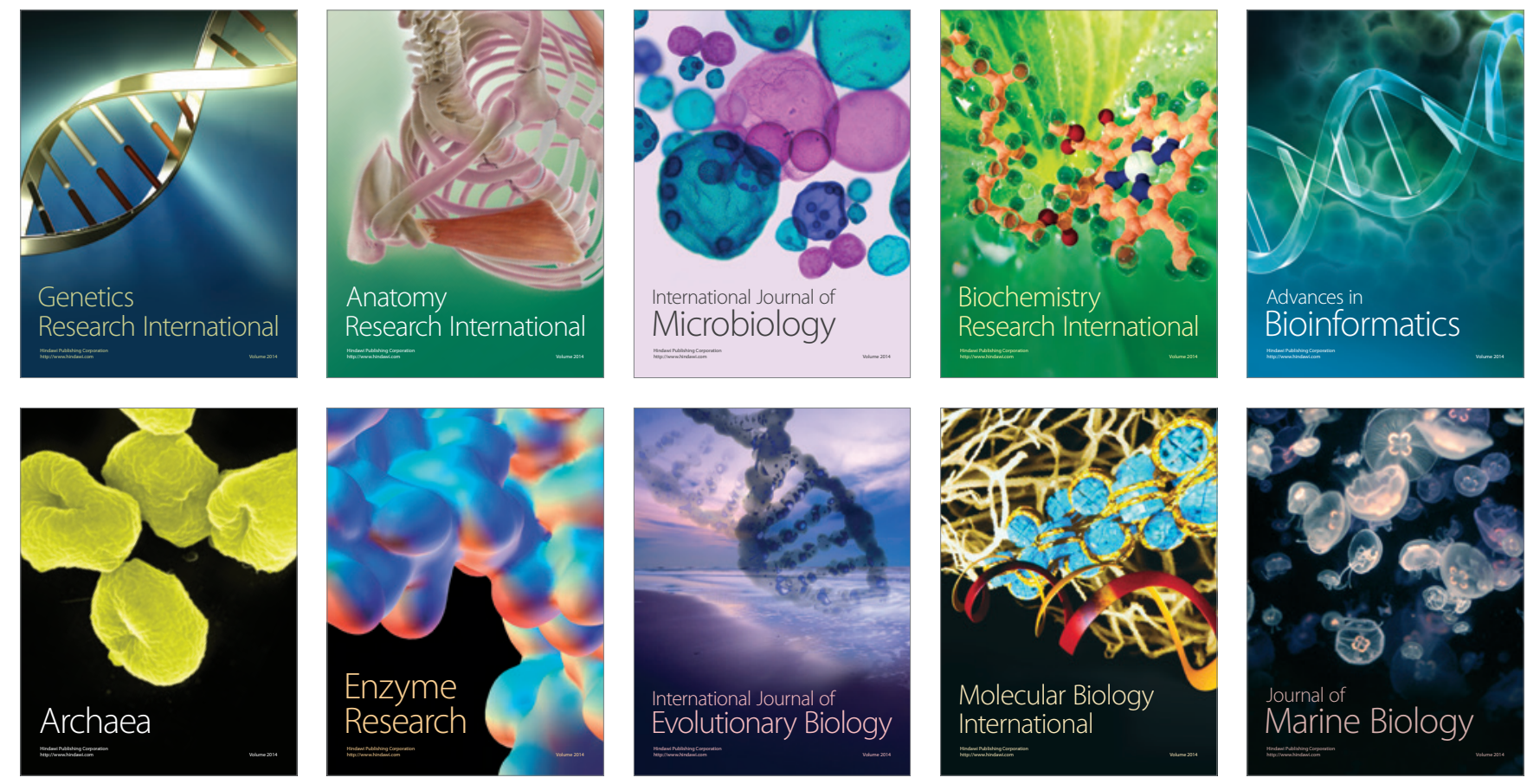